\title{
Altered Expression of a Chloroplast Protein Affects the Outcome of Virus and Nematode Infection
}

\author{
Elena E. Ganusova, ${ }^{1}$ J. Hollis Rice, ${ }^{2}$ Timothy S. Carlew, ${ }^{1}$ Akshita Patel, ${ }^{1}$ Emmanuel Perrodin-Njoku, ${ }^{3}$ \\ Tarek Hewezi, ${ }^{2}$ and Tessa M. Burch-Smith' ${ }^{1}$ \\ ${ }^{1}$ Department of Biochemistry and Cellular and Molecular Biology, University of Tennessee, Knoxville, TN 37996, U.S.A.; \\ ${ }^{2}$ Department of Plant Sciences, University of Tennessee; and ${ }^{3}$ National Technical Institute for the Deaf, Rochester Institute \\ of Technology, Rochester, NY 14623, U.S.A.
}

Accepted 19 March 2017.

The chloroplast-resident RNA helicase ISE2 (INCREASED SIZE EXCLUSION LIMIT2) can modulate the formation and distribution of plasmodesmata and intercellular trafficking. We have determined that ISE2 expression is induced by viral infection. Therefore, the responses of Nicotiana benthamiana plants with varying levels of ISE2 expression to infection by Tobacco mosaic virus and Turnip mosaic virus were examined. Surprisingly, increased or decreased ISE2 expression led to faster viral systemic spread and, in some cases, enhanced systemic necrosis. The contributions of RNA silencing and hormone-mediated immune responses to the increased viral susceptibility of these plants were assessed. In addition, Arabidopsis thaliana plants with increased ISE2 expression were found to be more susceptible to infection by the beet cyst nematode Heterodera schachtii. Our analyses provide intriguing insights into unexpected functional roles of a chloroplast protein in mediating plant-pathogen interactions. The possible roles of plasmodesmata in determining the outcomes of these interactions are also discussed.

There is abundant and increasing evidence that chloroplasts control multiple facets of plant defense (Bobik and BurchSmith 2015; Zhao et al. 2016). Chloroplasts are the source of the defense hormones salicylic acid (SA), jasmonic acid (JA) and its derivatives, and abscisic acid (ABA). They are also important for generating reactive oxygen species (ROS) and other redox-related molecules that are critical mediators of signaling during plant-pathogen interactions (Rojas et al. 2014; Sewelam et al. 2014; Torres et al. 2006). During defense responses, chloroplasts also generate retrograde signals that can modify expression of nucleus-encoded genes (Chan et al. 2016; Nomura et al. 2012). Moreover, recent studies have shown that chloroplasts can physically interact with nuclei and other cellular components through tubular extensions called stromules. Indeed, they are likely part of the mechanism of $\mathrm{N}$ immune receptor-mediated defense against Tobacco mosaic virus (TMV) (Caplan et al. 2008, 2015), and are also likely involved in infection by DNA viruses (Krenz et al. 2012).

Corresponding author: T. M. Burch-Smith; Telephone: +1.865 .974 .6203 ; Fax: +1.865.974.6306; E-mail: tburchsm@utk.edu

*The $e$-Xtra logo stands for "electronic extra" and indicates that eight supplementary figures, one supplementary table, and supplementary text are published online.

@ 2017 The American Phytopathological Society
Cell-to-cell communication in plants is also an emerging focus in studies of the plant defense response. Much is known about the role of plasmodesmata (PD) in various aspects of plant growth and development (Burch-Smith et al. 2012; Lucas and Lee 2004; Yadav et al. 2014), and it is becoming clear that through their roles in micro- and macromolecular trafficking PD are important players in defense (Faulkner 2013; Lee and Lu 2011; Lee 2015; Lim et al. 2016; Wang et al. 2013). Among plant pathogens viruses are best known for their use of the PDmediated symplasmic route for systemic spread during infection. The plant antiviral response includes the deposition of callose at the necks of PD to effectively restrict cell-to-cell spread (Ellinger et al. 2013; Lee 2015; Levy et al. 2007). Cyst nematodes (Heterodera and Globodera spp.) are another important group of plant pathogens in which PD play a key role in the etiology and structure of their feeding sites, the syncytia, formed in the root vascular tissues. The importance of PD to successful nematode parasitism was demonstrated by manipulating the level of callose deposited at syncytial PD; reduced callose degradation led to smaller syncytia and a higher femaleto-male ratio (Hofmann et al. 2010). The role of PD in modulating viral and nematode infections has been extended to almost all other classes of plant pathogens by recent findings demonstrating the importance of PD-mediated intercellular trafficking in systemic acquired resistance (Carella et al. 2015; Lim et al. 2016).

Since PD function is essential to plant survival, few mutants with abnormal PD function have been identified. Interestingly, one of these is a defect in the chloroplast-resident DEAH-type RNA helicase named INCREASED SIZE EXCLUSION LIMIT2 (ISE2) for its loss-of-function phenotype of increased PD-mediated trafficking (Burch-Smith and Zambryski 2010; Kim et al. 2002; Kobayashi et al. 2007). Arabidopsis ise 2 mutants have severely defective development, and some alleles led to arrested embryonic development (Kobayashi et al. 2007). Mutant ise 2 embryos have increased numbers of twinned and branched PD, as compared with wild-type embryos at the same developmental stage (Burch-Smith and Zambryski 2010). Nicotiana benthamiana leaves in which the ISE2 homolog has been silenced similarly contain a higher frequency of twinned and branched PD, compared with nonsilenced plants, and increased PD-mediated intercellular trafficking of fluorescent probes (Burch-Smith and Zambryski 2010).

Given that ISE2 is a chloroplast protein that can influence the formation and function of PD, the role of ISE2 in plant-pathogen interactions was investigated. Viral accumulation, spread, and disease induction were examined through ISE2 knockdown or overexpression in $N$. benthamiana plants. In addition, the effects 
of elevated ISE2 expression in Arabidopsis on beet cyst nematode infection were also determined. The results provide insight into the interplay between PD and chloroplasts in mediating plant defense responses to pathogens.

\section{RESULTS}

\section{ISE2 expression is increased upon TMV infection.}

The level of NbISE2 expression was examined in wild-type $N$. benthamiana plants in response to TMV or Turnip mosaic virus (TuMV) infection. Leaves were agroinfiltrated with cultures expressing either TMV or TuMV and samples were analyzed for ISE2 expression at $0,6,12,18$, and $24 \mathrm{~h}$ post-viral infection (hpi). NbISE2 expression was dramatically increased at $18 \mathrm{hpi}$ upon infection with either virus (Fig. 1A and B). Rubisco activase (RCA) and AtpC (ATP synthase- $\gamma$ subunit gene) are two other nuclear genes encoding chloroplast proteins, and both genes are involved in TMV infection (Bhat et al. 2013). Expression of $R C A$ and $A t p C$ is repressed in response to TMV infection (Bhat et al. 2013), a finding confirmed in our system (Supplementary Fig. S1).

\section{Silencing ISE2 increases susceptibility to TMV.}

Based on the phenotypes of increased intercellular trafficking and PD formation observed in plants depleted of ISE2, we hypothesized that decreased ISE2 expression would lead to increased local intercellular spread of viral pathogens and result in increased systemic spread. Tobacco rattle virus (TRV)-mediated virus-induced gene silencing (VIGS) was used to knock down ISE2 expression (Burch-Smith and Zambryski 2010). Fully expanded leaves of 5-week-old plants were then mechanically inoculated with plant sap containing $65 \pm 5$ infectious particles of TMV(30B)GFP (TMV-based vector 30B expressing green fluorescent protein). Development of systemic infection in the upper leaves of the infected plants was monitored for 4 days by the detection of GFP signal with UV light. Representative plants with systemic infection are shown in Figure 2A. At that time point, TMV(30B)-GFP had spread systemically in fewer than 5\% of TRV-infected, nonsilenced control plants, while approximately $40 \%$ of ISE2-silenced plants were systemically infected (Fig. 2B). Local intercellular movement of the virus in the TRV-infected, nonsilenced controls and ISE2silenced plants was quantified by imaging fluorescent lesions in the inoculated leaves at 4 days postinfection (dpi). The foci in ISE2silenced leaves were slightly larger than those on control leaves, although the difference was not statistically significant (Fig. 2C).

\section{Increased ISE2 expression enhances susceptibility to TMV.}

We had previously generated stable transgenic $N$. benthamiana lines expressing Arabidopsis ISE2 fused to GFP and expressed under the control of the constitutive Cauliflower mosaic virus 35S promoter (35S:AtISE2-GFP) (Burch-Smith et al. 2011). After assessing the level of transgene expression and AtISE2-GFP accumulation in 12 lines, two lines, OE1 and OE3, with consistently high levels of AtISE2 expression and ISE2-GFP accumulation were selected for further analysis. These lines appeared indistinguishable from wild-type $N$. benthamiana plants, and chloroplast development and function were apparently unaffected by increased ISE2 levels (Supplementary Fig. S2), except for increased starch accumulation in chloroplasts of overexpressing (OE) plants (Supplementary Fig. S3).

The effect of increased ISE2 expression on viral infection was examined in those lines. It is important to mention that, in these and subsequent experiments, wild-type and OE plants were agroinfiltrated with a nonsilencing TRV-VIGS vector when used in experiments that included TRV-ISE2, so that all plants used contained TRV (Supplementary Fig. S4). Thus, any effects could be attributed to the changes in ISE2 expression and not TRV infection. Four days after inoculation with TMV (30B)-GFP, almost $40 \%$ of OE1 plants and $60 \%$ of OE3 plants were systemically infected, compared with fewer than $5 \%$ of TRV-infected, nonsilenced control plants (Fig. 2B). The increased TMV(30B)-GFP spread in OE plants was confirmed in plants not containing TRV. TMV(30B)-GFP infection foci on OE1 and OE3 leaves tended to have smaller diameters than those on TRV-ISE2 and control infiltrated leaves (Fig. 2C). Interestingly, ISE2-GFP accumulated in the OE lines during TMV infection, despite transgene expression being driven by the 35 S promoter (Supplementary Fig. S5).

TMV infection also led to the development of systemic necrosis in both OE lines (Fig. 2D), with more than $60 \%$ of those plants displaying wilting, browning, and drying of the upper, systemically infected leaves (Fig. 2E). Strikingly, no necrotic symptoms were visible in TRV-infected, nonsilenced control, or ISE2silenced plants (Fig. 2D and E). Systemic necrosis is a consequence of the massive production of ROS and programmed cell death induced by SGT1 (SUPPRESSOR OF G-TWO ALLELE OF SKP1) and RAR1 (REQUIRED FOR MLA12 RESISTANCE) in complex with HSP90 (HEAT SHOCK PROTEIN OF $90 \mathrm{KDA}$ ) (Aguilar et al. 2015; Komatsu et al. 2010). Compared with nonsilenced, TRV-infected control, and TRV-ISE2 plants, SGT1 and $R A R I$ expression was more strongly induced in the ISE2-OE plants in response to TMV infection (Supplementary Fig. S6).

\section{ISE2 modulates susceptibility to TuMV.}

Next, we asked if ISE2 also modulates plant responses to other viruses. Representative plants systemically infected with the evolutionarily distinct virus TuMV expressing GFP (TuMVGFP), at $9 \mathrm{dpi}$, are shown in Figure 3A. Although the longdistance spread of TuMV was slower than that of TMV (9 versus $4 \mathrm{dpi}$ ), systemic invasion was significantly enhanced in one line overexpressing ISE2 (OE3) and in TRV-ISE2 plants compared with nonsilenced, TRV-infected control plants (Fig. 3B). The other line overexpressing ISE2 (OE1) was also systemically infected more frequently. Another characteristic of the infection caused by TuMV-GFP was necrosis of the vascular tissues, particularly in the petioles of the bottom leaves (Fig. 3C). Necrotic streaks appeared between 10 and 14 dpi on leaf petioles and major stems, causing the entire plant to wilt. By 14
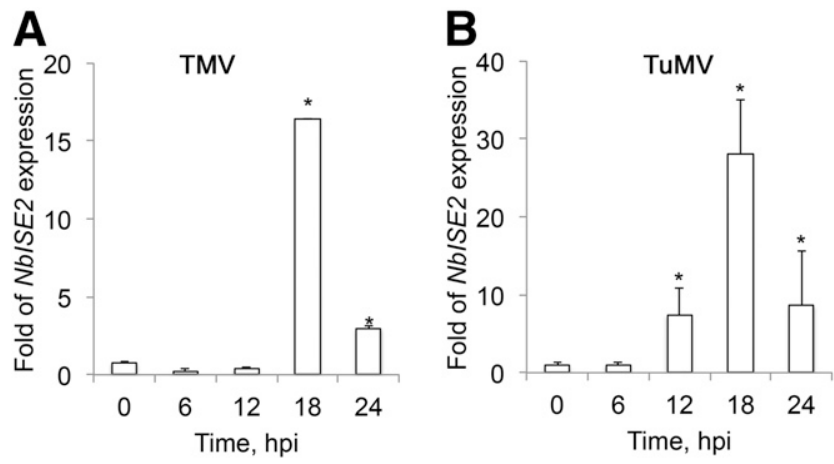

Fig. 1. Effect of Tobacco mosaic virus (TMV) and Turnip mosaic virus (TuMV) infection on ISE2 expression in wild-type Nicotiana benthamiana plants. A, The relative accumulation of NbISE2 mRNA in TMV(30B)GFP-inoculated leaves over $24 \mathrm{~h}$ was measured by quantitative polymerase chain reaction (qPCR). B, The relative accumulation of NbISE2 mRNA in TuMV-GFP-inoculated leaves over $24 \mathrm{~h}$ was measured by qPCR. Expression was normalized to mock-infected leaves. Results are representative of three biological replicates. Asterisks indicate $P$ values compared with control plants at $P<0.05$ (Student's $t$ test). cDNA was prepared from three leaves collected from three different plants. Error bars represent standard deviation. 
dpi, the majority of ISE2-silenced or ISE2-OE plants showed severe necrosis of the four oldest leaves compared with the control plants (Fig. 3D). TuMV has been shown to move systemically through xylem, which induces cell death of the phloem without affecting xylem integrity (Wan et al. 2015). Thus, altered ISE2 expression led to increased susceptibility to two unrelated viruses, TMV and TuMV.

\section{Arabidopsis plants overexpressing ISE2}

are more susceptible to cyst nematode infection.

ISE2 expression is higher in Arabidopsis shoots than in roots (Kobayashi et al. 2007). A previous transcriptome analysis of pure syncytial tissue isolated by microaspiration revealed that ISE2 expression was strongly induced by Heterodera schachtii compared with noninfected root tissues (Szakasits et al. 2009). Therefore, we measured ISE2 expression in $H$. schachtiiinfected roots over the course of syncytium development. At 3 dpi, ISE2 expression was about 3.7-fold higher in infected roots than in uninfected roots and this increased to approximately sixfold higher expression by 7 dpi (Fig. 4A). However, by 10 dpi, ISE2 expression in infected roots had returned to almost the same level as in uninfected control roots (Fig. 4A). The induction of ISE2 expression during the establishment phase of the $H$. schachtii infection supports the idea that ISE2 has an important role in this host-pathogen interaction and is consistent with the changes observed to ISE2 expression during viral infections.

Several Arabidopsis lines rescued by expression of the AtISE2-GFP transgene and, therefore, with varying levels of ISE2 expression (called RL lines) (Fig. 4B and C) (Kobayashi et al. 2007) were examined for their susceptibility to the beet cyst nematode $H$. schachtii. Ten-day-old plants were infected with juvenile stage 2 nematodes (J2) and the number of J4 females was scored 3 weeks later and used to determine nematode susceptibility levels. Three of the four lines examined showed statistically significant increases in nematode susceptibility compared with the wild-type Col-0 control plants (Fig. 4D). Moreover, the size and structure of the fully developed

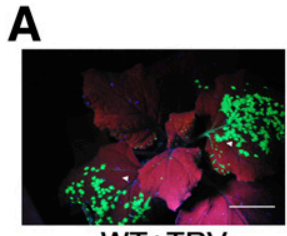

WT+TRV

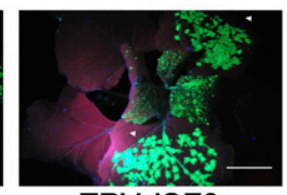

TRV-ISE2

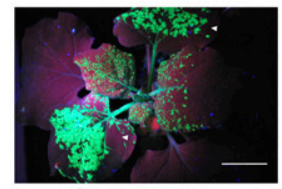

OE1+TRV

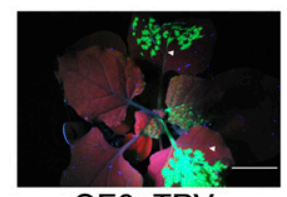

OE3+TRV
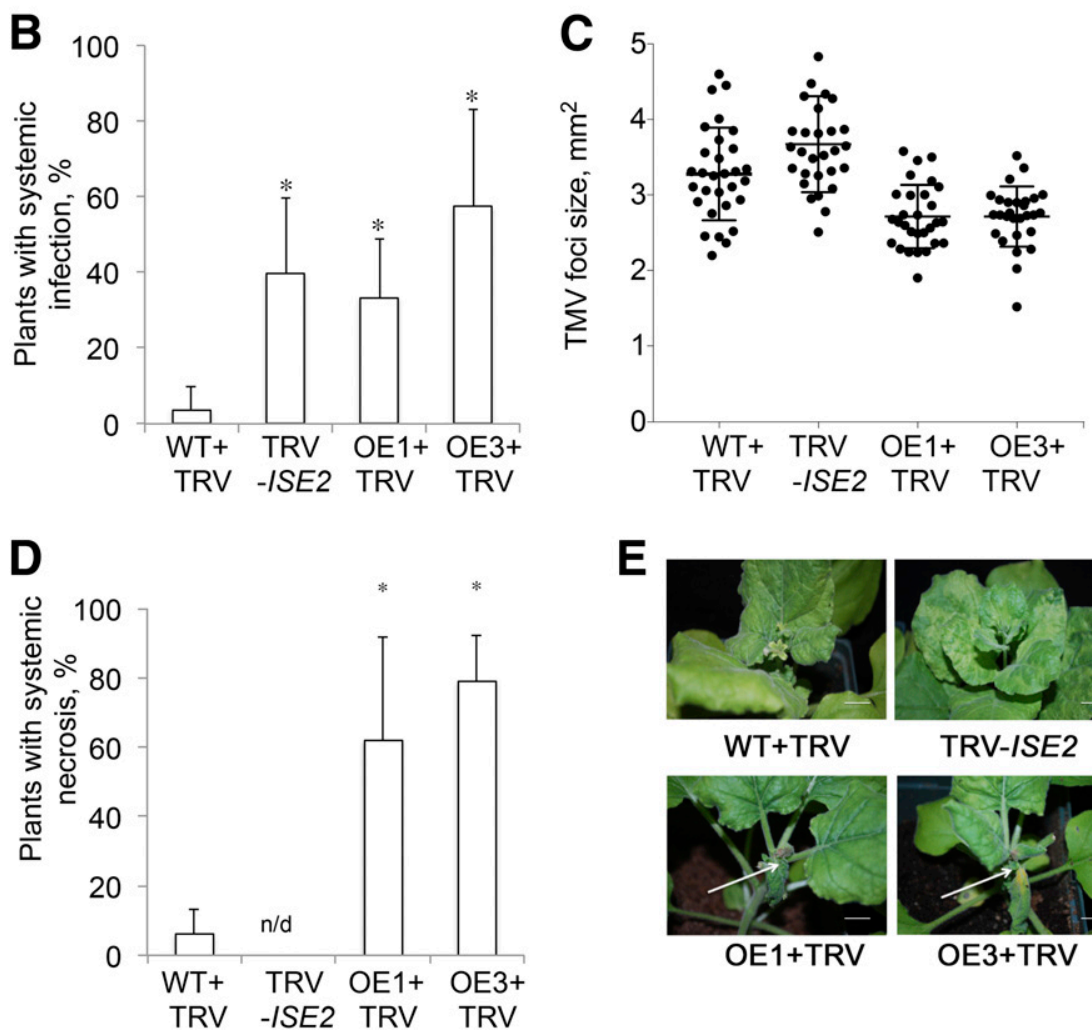

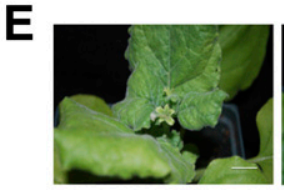

WT+TRV

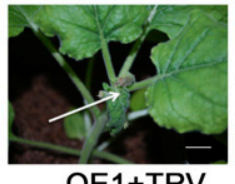

OE1+TRV

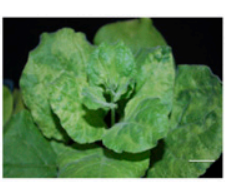

TRV-ISE2

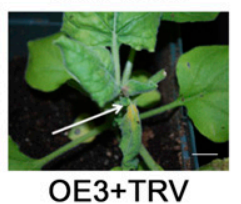

Fig. 2. Tobacco mosaic virus vector 30B-green fluorescent protein [TMV(30B)-GFP] infection of Nicotiana benthamiana plants. A, Representative images of control, TRV-ISE2, OE1, and OE3 plants showing systemic infection at 4 days postinfection (dpi) as detected with UV light. Scale bar $=3 \mathrm{~cm}$. The infected leaves are indicated with arrowheads. B, Quantitative representation of systemic infection in plants at 4 dpi. Asterisks indicate $P$ values compared with control plants at $P<0.05$ ( $Z$ test for two population proportions). Average number of systemically infected plants was calculated from at least six independent experiments; 10 plants of each plant line were used in each experiment. Error bars represent standard deviation. C, The distribution of the sizes of the fluorescent local lesions induced by TMV(30B)-GFP inoculated onto leaves and measured at 4 dpi. Bar markers indicate average foci size. $n=28$. D, Systemic necrosis induced by TMV in $N$. benthamiana plants at 9 dpi. Asterisks $\left(^{*}\right)$ indicate $P<0.05$ ( $Z$ test for two population proportions). Plants used for quantitation of systemic infection were monitored for systemic necrosis. Error bars represent standard deviation. E, Representative images of the plants imaged at 9 dpi. Stem necrosis and lodging of the apical regions indicated by white arrows. 
H. schachtii-induced syncytia (feeding sites) were monitored. In H. schachtii-infected Arabidopsis roots, callose accumulated along the outer cells of the fully developed syncytia and was much more prominent in the roots of RL plants, as detected by aniline blue staining (Fig. 4E). At 3 weeks after infection, syncytia on the roots of Arabidopsis RL plants were slightly larger than those on the control plants (Fig. 4F). Similar experiments examining the effects of reduced ISE2 expression were not possible, due to the unavailability of Arabidopsis tissue with the appropriate ISE2 knockdown. Nonetheless, the results with the rescued lines demonstrate that ISE2 is important for determining susceptibility to cyst nematode infection.

Given that both viral and nematode infections are known to depend on PD function and were both affected by changes in ISE2 expression, the effect of ISE2 overexpression on a pathogen that does not explicitly depend on PD trafficking was examined. For this, $N$. benthamiana TRV-ISE2-infected or OE plants were infected with the pathogenic bacteria Pseudomonas syringae DC3000. No differences in $P$. syringae DC3000 CFU or in expression of the NbPR5 marker gene were observed between control, ISE2-silenced, and OE plants at 4 dpi (Supplementary Fig. S7). Thus, overexpression of ISE2 appeared to dramatically influence susceptibility to two different types of pathogens whose successful invasion is PD-dependent, but there was no effect on pathogens whose invasion is PDindependent.
ISE2 is a negative regulator of intercellular trafficking.

In order to understand the altered pathogen susceptibility in ISE2-silenced and ISE2-OE plants, PD-mediated symplasmic trafficking in $N$. benthamiana plants with altered ISE2 expression was measured, using the passive diffusion of a fluorescent reporter molecule consisting of two tandem copies of GFP ( $2 \times$ GFP; molecular mass of $54 \mathrm{kDa}$ ) (Brunkard et al. 2015). Examples of fluorescent foci of different sizes formed by movement of $2 \times$ GFP from the primary transformed cell are provided in Figure 5A. We confirmed that silencing ISE2 increased intercellular movement of fluorescent marker proteins (Fig. 5) (Burch-Smith and Zambryski 2010). This increased symplastic flux could explain the increased systemic movement of TMV and TuMV in ISE2-silenced plants.

In the nonsilenced TRV-infected control plants, the $2 \times \mathrm{GFP}$ probe moved in about $38 \%$ of the foci (Fig. 5B) and almost no foci were extended to 3 or more cell layers (Fig. 5C), while in striking contrast $2 \times \mathrm{GFP}$ movement was significantly restricted in $\mathrm{OE}$ plants, with no movement of the $2 \times \mathrm{GFP}$ probe in about $54 \%$ of OE1 foci and $83 \%$ of OE3 foci (Fig. 5B), and no foci were larger than two cell layers in both lines (Fig. 5C). Further, silencing ISE2 expression led to increased probe movement from the epidermal to mesophyll layers of leaves (Fig. 5D), as previously reported (Burch-Smith and Zambryski 2010). However, increased ISE2 expression did not affect $2 \times$ GFP movement between leaf tissues. These data support ISE2's role

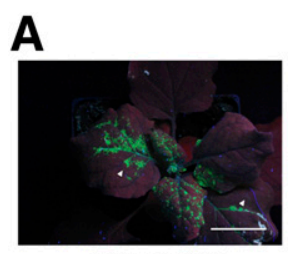

WT+TRV

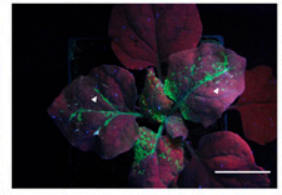

TRV-ISE2

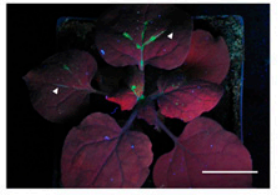

OE1+TRV

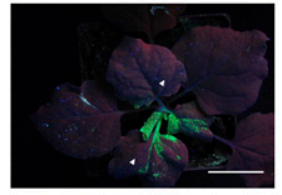

OE3+TRV
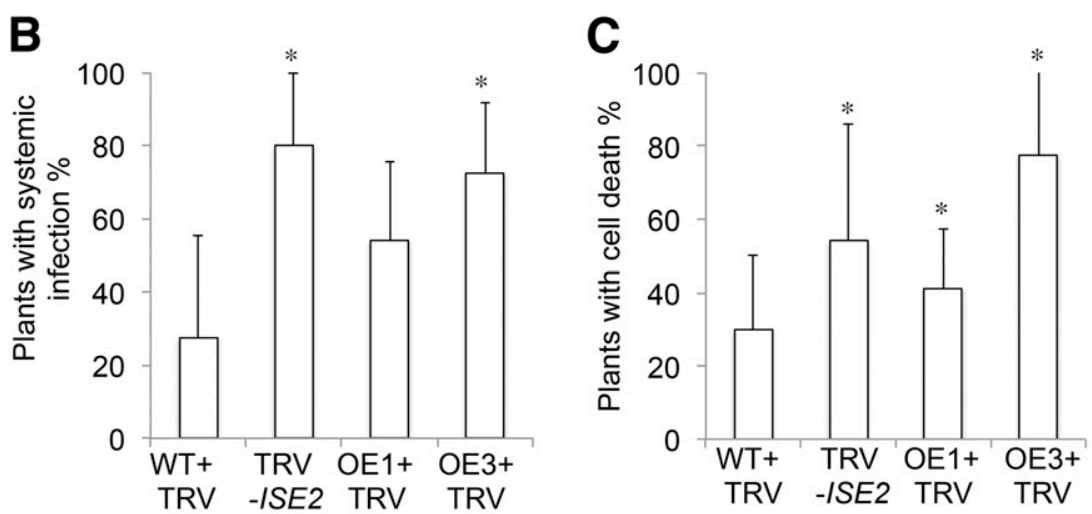

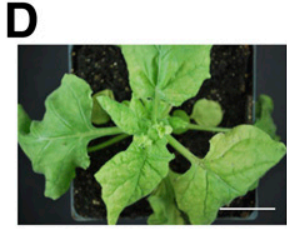

WT+TRV

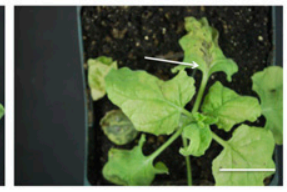

TRV-ISE2

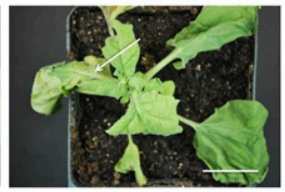

OE1+TRV

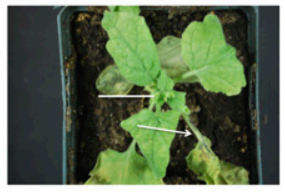

OE3+TRV

Fig. 3. Turnip mosaic virus-green fluorescent protein (TuMV-GFP) infection of Nicotiana benthamiana plants. A, Representative images of control, TRVISE2, OE1, and OE3 plants showing systemic infection at 9 days postinfection (dpi) as detected with UV light. Infected leaves indicated by arrowheads. Scale bar $=3 \mathrm{~cm}$. B, Quantitative representation of the appearance of systemic infection in plants at 9 dpi. Average number of systemically infected plants was calculated from at least three independent experiments; 10 plants of each plant line were used in each experiment. Asterisks indicate $P$ values compared with control plants at $P<0.05$ ( $Z$ test for two population proportions). Error bars represent standard deviation. C, Quantitation of plants with cell death at 14 dpi. Plants used for quantitation of systemic infection were monitored for systemic necrosis. Asterisks indicate $P$ values compared with control plants at $P<0.05$ ( $Z$ test for two population proportions). Error bars represent standard deviation. D, Representative images of TuMV-GFP-infected plants; necrotic regions on the older leaves are indicated with white arrows. Scale bar $=3 \mathrm{~cm}$. 
as a negative regulator of PD-mediated intercellular trafficking. However, they do not explain the increased pathogen susceptibility of those plants.

The regulated deposition and removal of the polysaccharide callose at the necks of PD is a major mechanism for modulating PD-mediated intercellular trafficking. Callose deposition decreases plasmodesmal flux (Levy et al. 2007). Therefore, we measured callose levels at PD by aniline blue staining. ISE2silenced leaves contained fewer aniline blue foci than did nonsilenced TRV-infected control plants (Fig. 5E). Intriguingly, OE plants also had significantly fewer aniline blue foci than did TRV-infected control plants (Fig. 5E), despite having reduced intercellular trafficking. This is in contrast to the observed increase in callose deposition in $H$. schachtii-induced syncytia (Fig. 4D). Together, the data suggest that the mechanism used by ISE2 to alter intercellular trafficking does not depend solely on callose.

\section{Factors leading to increased susceptibility} in plants with increased ISE2 expression.

We hypothesized that the enhanced pathogen susceptibility of plants with increased ISE2 expression could be attributed to changes in chloroplast-mediated defense responses instead of to PD. The chloroplast hormones SA, JA, ABA, and auxin have been implicated in antiviral defense (Alazem and Lin 2015). The expression of marker genes that reflect the activity of pathways induced by these hormones was, therefore, monitored in leaves 48 hpi with TMV. The PR5 marker for SA-activated pathways revealed no difference between TRV-infected, nonsilenced control plants and plants with elevated ISE2 expression (Fig. 6A). Similarly, ABA-induced ABII expression was not differentially affected between control and OE plants. In contrast, expression of the PDF1.2 marker of JA signaling was significantly induced in TMV-infected OE plants compared with similarly infected control plants (Fig. 6C). In addition, the concentrations of these hormones in 4-week-old plants in the presence or absence of TMV infection were measured. Uninfected OE3 plants overexpressing ISE2 had smaller amounts of ABA, SA, and auxin (indole 3-acetic acid) than wild-type plants, while JA and its derivatives (JA-isoleucine [JA-Ile], 12oxophytodienoic acid) were not detected in either set of plants. Meanwhile, consistent with the gene expression analysis OE3 plants infected with TMV(30B)-GFP had significantly more JA-Ile but lower levels of ABA than did wild-type plants. There was no difference in SA or auxin content between control and OE3 plants during infection (Supplementary Fig. S8).
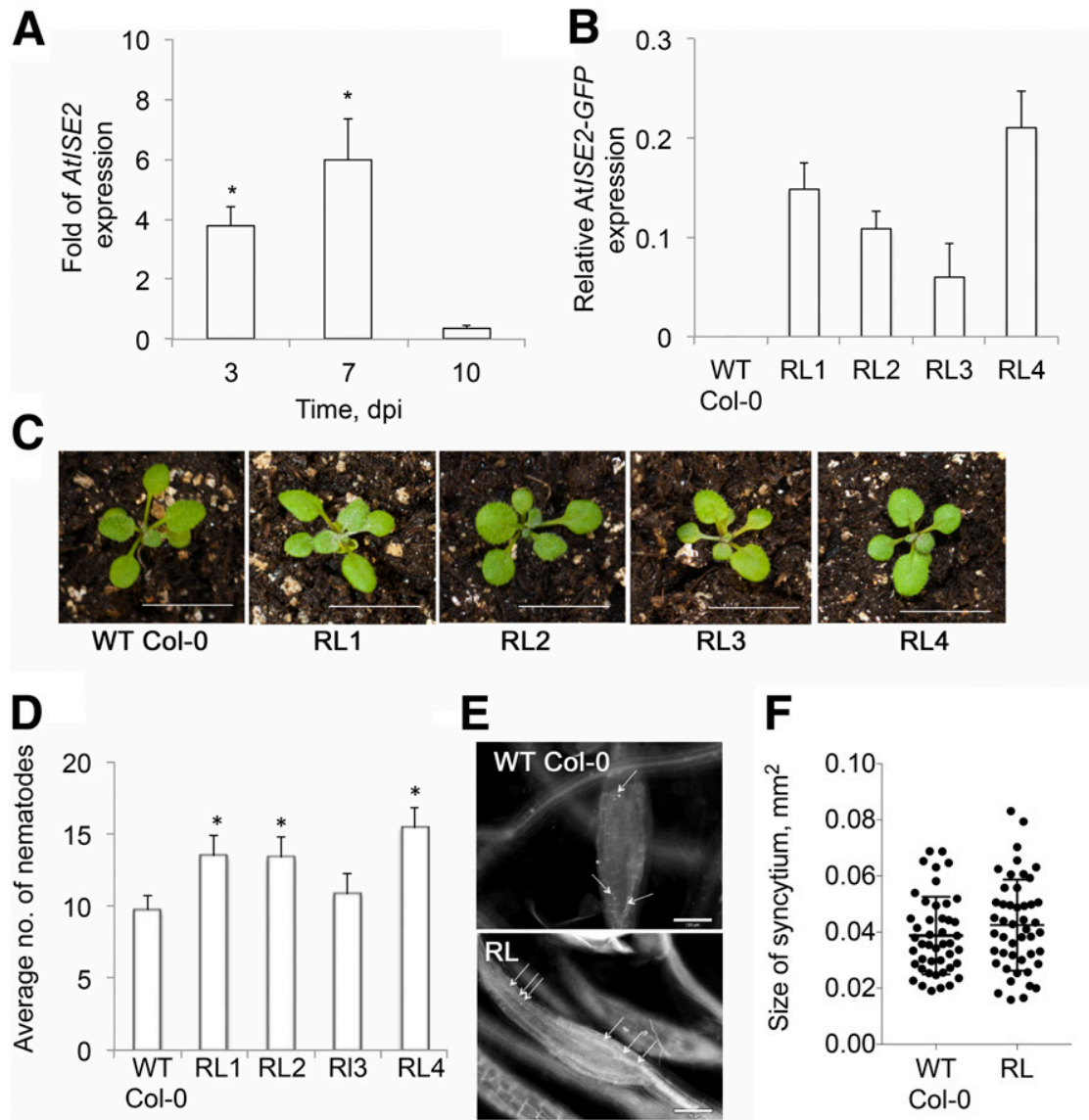

Fig. 4. Nematode infection in Arabidopsis plants with increased ISE2 expression. A, Expression of ISE2 in Heterodera schachtii-infected roots relative to uninfected roots measured by quantitative polymerase chain reaction (qPCR). Expression levels were normalized against $A C T I N 8$ as an internal reference. Error bars represent standard deviation from three biological replicates and asterisks indicate statistically significant difference from 1.0 (no change; $P<0$. 05 , Student's $t$ test). B, Validation of ISE2-GFP (green fluorescent protein) expression by qPCR. Error bars represent standard deviation. C, Representative images of 3-week-old ISE2-GFP overexpressing rescued lines (RL). Scale bar $=10 \mathrm{~mm}$. D, Transgenic Arabidopsis plants overexpressing ISE2 revealed increased susceptibility to H. schachtii. RL seeds were planted on modified Knop's medium, and 10-day-old seedlings were inoculated with approximately 250 surfacesterilized $\mathrm{J} 2 \mathrm{H}$. schachtii nematodes. Three weeks after inoculation, the number of $\mathrm{J} 4$ females per root system was determined. Data are presented as the mean \pm standard error $(n=20)$. Asterisks indicate statistically significant differences (indicated by asterisks [ $\left.{ }^{*}\right], P<0.05$, Student's $t$ test, $\left.n=3\right)$. E, Representative images of syncytia formed by $H$. schachtii. Arrows indicate callose deposition in the cell walls of syncytia, as determined by aniline blue staining. Scale bar = $130 \mu \mathrm{m}$. F, Average size of syncytia formed by $H$. schachtii in the roots of control and RL plants. Error bars represent standard deviation, $n=47$ each for control and RL. 
A second hypothesis tested was that overexpression of ISE2 could interfere with the host small interfering RNA (siRNA)mediated antiviral defense response. To this end, accumulation of mRNA transcripts of a subset of genes that play crucial roles in the antiviral siRNA response, RDR6 (RNA-DEPENDENT RNA POLYMERASE 6), SGS3 (SUPPRESSOR OF GENE SILENCING 3), and DCLA (ENDORIBONUCLEASE DICERLIKE 4) was measured 24 hpi with TMV. Strikingly, the two OE lines displayed different responses of the siRNA machinery to TMV infection for $S G S 3$ and $R D R 6$ expression. While the OE1 line showed enhanced expression of SGS3 and RDR6 during infection, expression of both genes was suppressed in the OE3 line (Fig. 6E and F). We interpret this to mean that $S G S 3$ and $R D R 6$ are likely not playing a role in the enhanced viral susceptibility observed in those lines. In contrast, expression of DCL4 was less strongly induced in both OE lines compared with wild-type tissues (Fig. 6D). Perhaps the reduced expression of DCLA in those tissues could account for a compromised antiviral response in those lines, leading to enhanced susceptibility. Together, these data indicate that ISE2 expression affects other aspects of the plant defense machinery, and these combined changes could be, at least partly, responsible for the increased pathogen susceptibility of plants with increased ISE2 expression.

\section{DISCUSSION}

In this study, we have shown that increased or decreased ISE2 expression enhanced susceptibility to pathogen infections. The chloroplast RNA helicase ISE2 is important for the development and function of both chloroplasts and PD; loss of ISE2, required for the splicing of at least a subset of chloroplast group II introns (Carlotto et al. 2016), results in defective chloroplasts with reduced thylakoid formation, increased stromal volume, and, ultimately, leaf chlorosis (Burch-Smith et al. 2011), and ISE2 knockdown leads to increased intercellular trafficking and defects in plasmodesmal biogenesis, notably increased formation of twinned and branched PD (Burch-Smith and Zambryski 2010; Kobayashi et al. 2007). Both chloroplasts and PD have important roles in mediating the outcome of plant-pathogen interactions. Interestingly, ISE2 expression was induced by viral infection (Fig. 1), suggesting that it could have a role in plant-virus interactions. Similarly, nematode infection also induced ISE2 expression (Fig. 5). We, therefore, investigated ISE2's role in plant-pathogen interactions.

We hypothesized that plants with reduced ISE2 expression would be more susceptible to infection by pathogens. Viruses use PD for their cell-to-cell spread at sites of infection, to enter the vasculature and, again, to exit the vasculature in sink tissues (Heinlein 2015; Hipper et al. 2013) and chloroplasts have important roles in viral replication and spread in their plant hosts, including defense hormone production (Murphy and Carr 2002; Zhao et al. 2016). First, we considered it likely that viruses would be able to spread cell-to-cell more easily in ISE2-silenced leaves than in leaves with normal ISE2 levels, since there would be more PD available for intercellular spread. TMV moves between cells as a ribonucleoprotein complex (Heinlein et al. 1998), while TuMV moves via tubules derived from the viral coat protein (Wan et al. 2015). The ability of both viruses to move faster in ISE2-silenced plants suggests that there is a general defect in the control of PD trafficking in those plants. Second, the defective chloroplasts in ISE2-silenced leaves could have resulted in compromised or diminished responses to viral infection. It has long been known that the chlorotic and mosaic phenotypes associated with viral infection are due to disrupted chloroplast function (Manfre et al. 2011). Indeed, the susceptibility of $N$. benthamiana to TuMV was found to depend on the amount of light available to infected plants and the function of the photosynthetic machinery (Manfre et al. 2011). It is also known that viruses recruit chloroplast proteins during infection. This is exemplified by the small subunit of Rubisco RbcS, which interacts with the Tomato mosaic virus (ToMV) movement protein and is required for local cell-to-cell spread during infection (Zhao et al. 2013). In addition, several chloroplast proteins have been implicated in defense against viral infection (Reinero and Beachy 1986, 1989; Schoelz and Zaitlin 1989). For example, AtpC and RCA are nucleus-encoded chloroplast proteins that physically interact with TMV replicases (Bhat et al. 2013) and reduced expression of either protein decreased viral accumulation and local spread, revealing that these proteins normally act to limit susceptibility to tobamoviruses. Another important function of chloroplasts during defense responses is the production of ROS (Bobik and Burch-Smith 2015). Chloroplasts in ISE2-silenced leaves are in a more reduced state compared with nonsilenced control plants (Stonebloom et al.
A

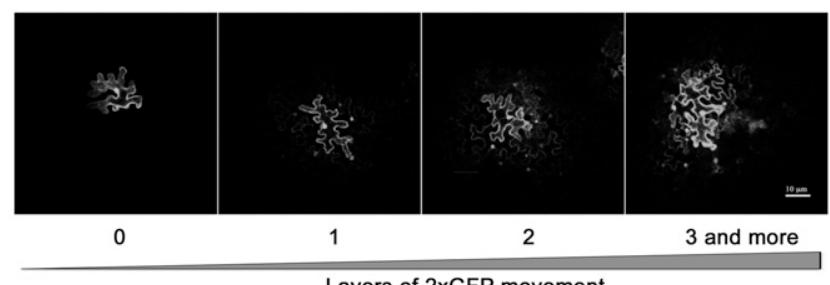

Layers of 2xGFP movement
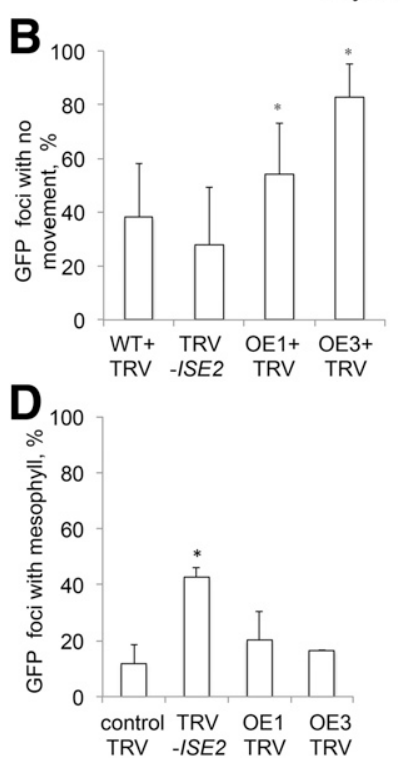

C
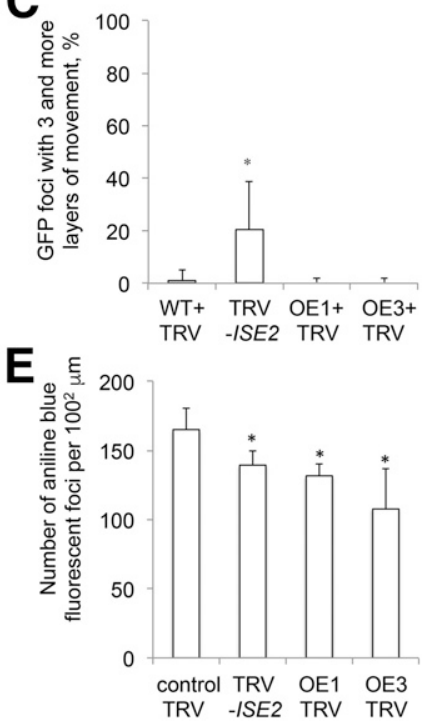

Fig. 5. Cell-to-cell movement of $2 \times$ GFP in Nicotiana benthamiana plants with various levels of ISE2 expression. A, Examples of $2 \times$ GFP movement between cell layers. Images are three-dimensional projections of Z-stacks. Scale bar $=10 \mu \mathrm{m}$. B, Fraction of foci showing no movement of $2 \times$ GFP. ISE2-overexpressing plants show decreased $2 \times$ GFP movement compared with nonsilenced control plants. C, Number of foci with three or more layers of $2 \times$ GFP movement is increased in ISE2-silenced plants. D, Number of foci showing $2 \times$ GFP movement from epidermal to adjacent mesophyll cells is increased in plants with decreased ISE2 expression. Average number of fluorescent foci was calculated from at least five independent experiments in which a minimum of 10 foci was scored. Error bars represent standard deviation. E, Number of aniline blue foci detected per $100 \mu^{2}$ of cell wall, as measured from single images of a Z-stack collected by confocal microscopy. Error bars represent standard deviation over three independent experiments. For B through E, asterisks indicate statistically significant differences compared with control plants, at $P<0.05$ ( $Z$ test for two population proportions). 
2012). Due to their reduced thylakoid content and photosynthetic capacity (Burch-Smith et al. 2011), it seems unlikely that chloroplasts in ISE2-silenced leaves would be able to generate significant amounts of ROS during viral infection. Conversely, perhaps the increased ISE2 levels in the ISE2-OE lines leads to increased ROS production. Indeed it has been shown that increased oxidation of chloroplasts leads to decreased intercellular trafficking (Benitez-Alfonso et al. 2009; Stonebloom et al. 2012) This could explain the systemic necrosis observed in the OE lines infected with TMV but not in the ISE2-silenced lines (Fig. 2). However, this does not explain the systemic necrosis observed in all lines in response to TuMV infections (Fig. 3). Nonetheless, our hypothesis was confirmed by the finding that reduced ISE2 expression led to increased viral systemic spread during infection (Figs. 2 and 3).

In contrast, we predicted that increased ISE2 levels would lead to decreased susceptibility to viruses and other pathogens. This prediction was based on ISE2's role as a negative regulator of intercellular trafficking (Burch-Smith and Zambryski 2010; Kobayashi et al. 2007). Indeed, plant lines ectopically expressing AtISE2 markedly decreased intercellular trafficking of GFP probes (Fig. 5). However, increasing ISE2 levels led to unexpected outcomes of plant-virus and plant-cyst nematode interactions, with increased susceptibility to both viruses (Figs. 2 and 3) and nematodes (Fig. 4). Studies of syncytia induced by H. schachtii in Arabidopsis roots have suggested that there is temporal regulation of PD formation and intercellular trafficking during syncytium formation (Hofmann and Grundler 2006; Hofmann et al. 2010; Hoth et al. 2005, 2008). However, the roles of PD and intercellular communication during nematode infection remain largely unexplored.

Transgenic $N$. benthamiana plants expressing both endogenous NbISE2 and AtISE2-GFP (OE plants) were morphologically similar to nonsilenced control $N$. benthamiana plants. The levels of the photosynthetic pigments and the quantum efficiency of photosystem II in OE plants were similar to those of
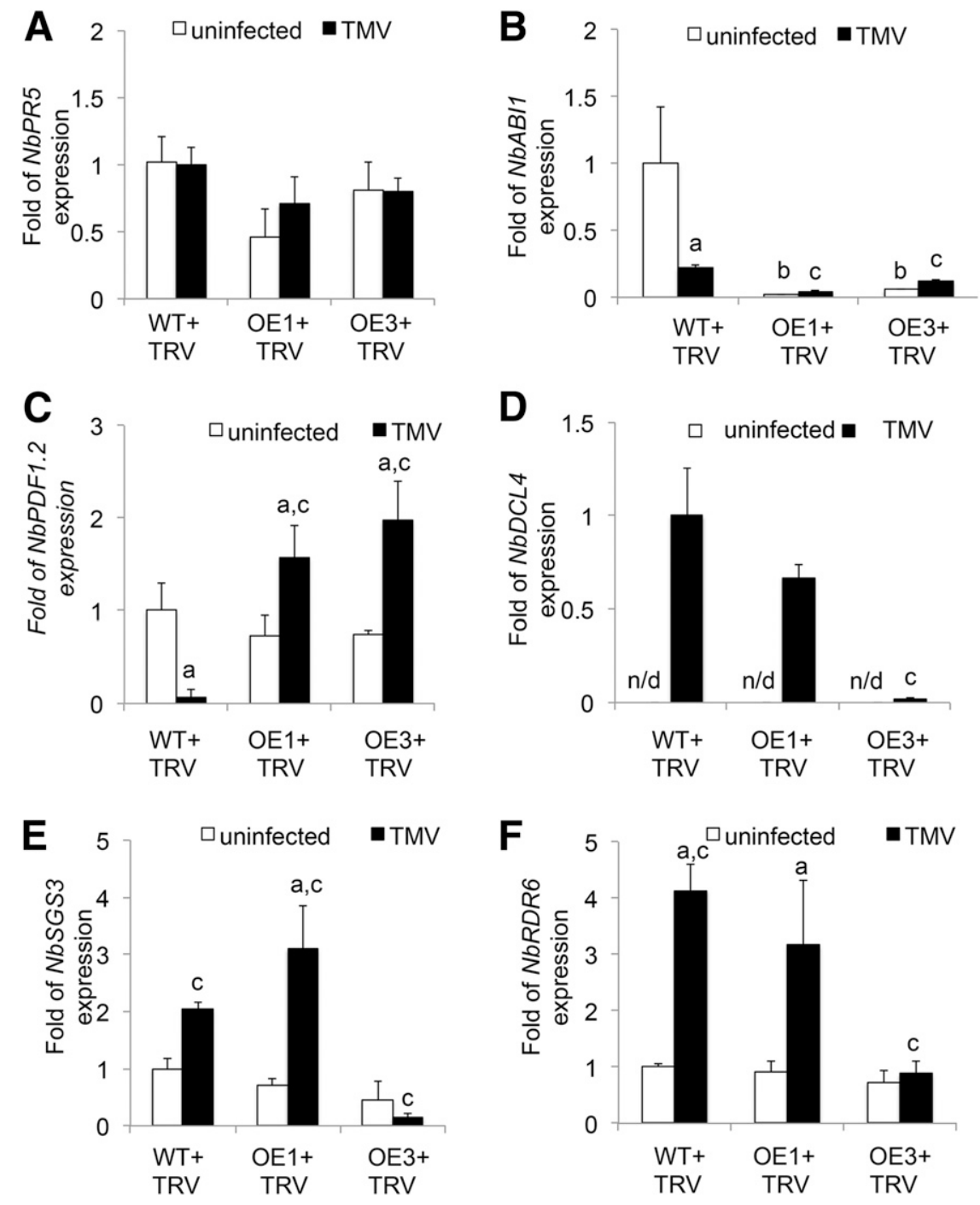

Fig. 6. Quantitative polymerase chain reaction (qPCR) quantification of key marker genes associated with viral infection in plants with increased $I S E 2$ expression. A, Expression of $N b P R 5$ marker gene for SA-mediated defense signaling, $\mathbf{B}, N b A B I 1$ marker for ABA-mediated defense signaling, and $\mathbf{C}, P D F 1.2$ marker for JA-mediated defense signaling was measured by qPCR. RNA was isolated from uninfected tissue or tissue collected $48 \mathrm{~h}$ after Tobacco mosaid virus (TMV) infection. D to F, Expression of genes encoding components of the RNA silencing machinery. Expression of $N b D C L 4$ (D), $N b S G S 3$ (E), and $N b R D R 6$ (F) was measured by qPCR. RNA was isolated from uninfected tissue or tissue collected $24 \mathrm{~h}$ after TMV infection. Expression was normalized to uninfected wild-type (WT) leaves. Error bars represent standard deviation. Results are representative of three biological replicates. Lower case letters denote the following: a, statistically significant difference between uninfected and infected tissues of a given line; b, statistically significant difference between uninfected WT and OE tissues; and c, statistically significant difference between TMV-infected WT and OE tissues. Statistical significance was $P<0.05$ (Student's $t$ test). 
nonsilenced control plants. At the ultrastructural level, the chloroplasts of newly emerged OE leaves differed only in the presence of large starch granules, as compared with the chloroplasts of wild-type control leaves of the same age. Similarly, Arabidopsis RL expressing AtISE2-GFP were also identical in appearance to wild-type plants (Fig. 4). This suggests that the chloroplasts in OE plants were competent for photosynthesis, at least under our growth conditions. Nonetheless, our analysis revealed that $N$. benthamiana plants with increased ISE2 expression displayed enhanced activation of JA-responsive gene expression in response to infection (Fig. 6). JA is a derivative of linoleic acid whose synthesis begins in the chloroplast but is completed in peroxisomes. JA has been reported to act through suppression of SA-mediated resistance to increase susceptibility of tobacco plants to TMV (Oka et al. 2013). Thus, while the chloroplasts in plants with increased ISE2 expression appear normal, they likely have altered hormone metabolism and signaling. Understanding the effects of altered ISE2 expression on chloroplast lipid metabolism could help illuminate the response of these plants to infection. An intriguing observation in OE plants is the reduced induction of expression of the DCL4 component of the RNA silencing machinery. Thus, ISE2 could act indirectly to increase susceptibility to pathogens, through its role in modulating chloroplast signaling and hormone production.

Given that ISE2 expression was increased in response to viral infection (Fig. 1) and that the ISE2-GFP protein accumulated in chloroplasts during infection, it is possible that ISE2 could have a direct role as a host factor for viral replication and spread. As mentioned above, several chloroplast proteins are known to have positive roles in establishing viral infections. Although we have not observed its accumulation outside the chloroplast during infection, it cannot be ruled out that viruses recruit ISE2 to their sites of replication or spread or both. Further experiments will specifically address ISE2's interaction with viral proteins to address the possibility of this RNA helicase being co-opted into virus replication and possibly spread.

How might decreased intercellular trafficking lead to increased susceptibility to pathogens? Occlusion of PD to reduce intercellular trafficking has been shown to be a successful strategy to limit viral infection. Overexpression of $R G P 2$ led to its accumulation at PD and reduced TMV spread (Zavaliev et al. 2010). Similarly, overexpression of the membrane raft protein Remorin, which also localizes to PD, led to decreased Potato virus $X$ spread in tomato (Raffaele et al. 2009). The PDLOCALIZED PROTEIN5 (PDLP5) belongs to a family of eight type I membrane receptors (Bayer et al. 2006; Thomas et al. 2008). PDLP5 overexpression in $N$. benthamiana delayed systemic spread of TMV but not Cucumber mosaic virus (CMV) (Lee et al. 2011). In stark contrast, the decreased intercellular trafficking caused by increased ISE2 expression (Fig. 5) did not compromise viral local intercellular spread or systemic movement (Figs. 2 and 3). This finding suggests that limited PD trafficking capacity may, in some situations, be sufficient for virus intercellular and eventual systemic spread. It should be noted that, unlike the aforementioned proteins, ISE2 localizes to chloroplasts and not to PD, indicating that there are different mechanisms to restrict PD flux. Also, our data suggest that ISE2's role in regulating PD flux is not solely accomplished through the regulated deposition or removal of callose at the necks of PD (Fig. 5).

In addition to the controlled formation of new PD, the regulated deposition and removal of callose at PD is also crucial to determining the outcome of cyst nematode syncytia formation. Callose was detected at PD in the cell walls of the syncytial margins, and the amount of callose detected gradually decreased from day 4 to day 7 of infection (Hofmann et al. 2010).
An Arabidopsis mutant with a T-DNA insertion in the $A t B G \_P P A P$ gene encoding a $\beta$-1,3-glucanase and, hence, reduced callose removal from PD was able to limit the size of syncytia and showed a smaller female/male ratio than wild-type plants (Hofmann et al. 2010). Similarly, overexpression of the RAP2.6 transcription factor led to increased callose deposition and smaller syncytia (Ali et al. 2013). Based on these previous findings, we had expected that overexpression of ISE2 would confer enhanced resistance to $H$. schachtii infection. The observation that Arabidopsis RL plants with reduced intercellular trafficking were more susceptible to $H$. schachtii infection (Fig. 4) was, therefore, unexpected.

We propose two possibilities for how increased ISE2 expression could lead to enhanced nematode infection. The first possibility is that either hormone production, distribution, or both are compromised in RL roots. The phytohormones auxin (Hewezi 2015, 2014), cytokinin (Shanks et al. 2016; Siddique et al. 2015), and ethylene (Wubben et al. 2001, 2004) have critical roles in successful nematode infection. Auxin moves symplasmically via PD (Coudert et al. 2015; Han et al. 2014), and mutants with altered callose synthesis had defective auxin distribution (Han et al. 2014). Long-distance movement of cytokinin has also been demonstrated, and this was disrupted by callose accumulation at PD (Bishopp et al. 2011). The decreased PD flux in RL roots could alter auxin and cytokinin flux in those roots, locally increasing their levels and leading to increased susceptibility to nematode infection. There is also evidence that other defense molecules move systemically from shoot to root (Kehr and Buhtz 2008; Lim et al. 2016) and that PD have a significant role in this process. The second possibility recalls the accumulated starch in chloroplasts of ISE2-RL sink leaves, likely due to altered carbohydrate metabolism or partitioning. Perhaps, similar to the young sink leaves in those plants, there are increased carbon levels in the Arabidopsis RL roots. At early times of infection, the $\mathrm{J} 2$ nematodes would, therefore, have access to elevated nutrient levels, allowing for its faster development. In this scenario, the growth of the nematode would simply outpace the plant's ability to launch an effective defense response. Perhaps the disrupted intercellular trafficking combined with defective defense-hormone production result in a compromised defense response against nematodes.

\section{Conclusion.}

Taken together, our results demonstrate that ISE2 affects the structure and function of chloroplasts, which, in turn, affects cellto-cell communication via PD, a phenomenon we previously termed ONPS (Burch-Smith et al. 2011). We have shown that the level of ISE2 expression can modulate plant defense responses. Although low or high expression of ISE2 affects symplastic transport in different ways, the outcome of the compromised defense response is unambiguous. These observations apply to pathogens whose life cycle is strictly dependent on symplastic transport. A practical outcome of this study is that chloroplastPD crosstalk may result in severely compromised plant immunity. In total, the data presented here reveal a complex relationship between PD and chloroplasts, especially with respect to pathogen susceptibility and the outcomes of infection. They also suggest there are unknown connections between different defense mechanisms and that the cell integrates these signals to produce a final outcome that cannot be determined prima facie. As we move to engineer plants with altered carbon partitioning or chloroplasts in attempts to optimize plant productivity to better fit human needs, care must be taken to ensure that these changes do not inadvertently compromise plant disease resistance. 


\section{MATERIALS AND METHODS}

Plant materials, VIGS, virus strains, and virus inoculations.

Nicotiana benthamiana plants were grown on light carts at $28 \pm 1^{\circ} \mathrm{C}$ with $16 \mathrm{~h}$ of light (approximately $172 \mu \mathrm{mol} \mathrm{m} \mathrm{m}^{-2} \mathrm{~s}^{-1}$ ) and $22 \pm 1^{\circ} \mathrm{C}$ in $8 \mathrm{~h}$ of dark. Arabidopsis thaliana plants were grown on plates in a growth chamber, as described in the infection assay.

The construct used to silence ISE2 was described previously (Burch-Smith and Zambryski 2010). VIGS was done according to published protocols (Liu et al. 2004). Briefly, two leaves of 3-week-old N. benthamiana plants were infiltrated with Agrbacterium tumefaciens cultures carrying relevant TRV constructs. Plants were kept on light carts for 2 weeks, until assays were performed or samples collected. Photographs of plants were taken with a Nikon D60 camera (Nikon, Inc.). For assays involving time courses, infected leaves were detached from the plants after 16, 22, 28, 34, and $40 \mathrm{~h}$. Allowing $16 \mathrm{~h}$ for Agrobacterium-mediated T-DNA transfer, this corresponded to 0,6 , 12,18 , and $24 \mathrm{~h}$ of viral infection.

To check replication and systemic movement of TMV(30B)GFP, TRV-ISE2, OE1, and OE3 $N$. benthamiana plants were inoculated with sap from TMV(30B)-GFP agroinfiltrated leaves of the same species. Plant sap containing viruses were obtained by grinding infected leaf tissue with a mortar and pestle and were diluted by the addition of approximately 2 volumes of sterile deionized water. Viral extracts were inoculated directly to plants with a sterile sponge, as described previously (Dinesh-Kumar et al. 2000). For expression of TMV, agrobacteria containing the U1 strain of TMV were infiltrated into plants at an optical densidty at $600 \mathrm{~nm}\left(\mathrm{OD}_{600}\right)=1.0$, after resuspending in inoculation medium (10 mM MES, $10 \mathrm{mM}$ $\mathrm{MgCl}_{2}, 200 \mu \mathrm{M}$ acetosyringone). Plants were evaluated for symptoms for 9 days. GFP expression was visualized by illumination with a hand-held long-wave UV lamp, as previously described (Liu et al. 2004). TuMV-GFP (Lellis et al. 2002) was agroinfiltrated at $\mathrm{OD}_{600}=1.0$ to infect plants. Plants infected with TuMV were monitored for the development of systemic infection and necrosis for 14 days.

\section{RNA extraction and quantitative reverse transcription- polymerase chain reaction (qRT-PCR) analysis.}

Total RNA from leaf tissues was extracted using Trizol Reagent (Thermo Fisher Scientific) and was treated with DNase I (Ambion). First-strand cDNA was synthesized using 21-base oligo (dT) primer (Invitrogen) or random Primer mix (New England Biolabs). Fivefold diluted cDNA $(2.5 \mu \mathrm{l}), 0.5 \mu \mathrm{l}$ of each gene-specific primer (Supplementary Text; Supplementary Table S1), and $5 \mu$ l of the Power SYBR green master mix (Applied Biosystems) were used in 10- $\mu$ l reactions for qRTPCR analyses of mRNA levels of with an iQTM5 multicolor RT PCR detection system (Bio-Rad). To normalize the mRNA levels of target genes between samples, relative actin mRNA levels were determined, using actin-specific primers and a relative quantification method (Pfaffl 2001). The efficiency of the primers used in qPCR was no lower than $92 \%$.

\section{H. schachtii infection assay.}

Seeds of four independent homozygous transgenic lines overexpressing ISE2 (T3 generation) along with the wild-type Arabidopsis ecotype Col-0 were surface-sterilized and were planted on modified Knop's medium (Sijmons et al. 1991) in 12-well tissue culture plates (BD Biosciences). Each line was replicated 20 times in a randomized complete block design. Plants were grown in a growth chamber at constant temperature of $24^{\circ} \mathrm{C}$ under $16 \mathrm{~h}$ of light and $8 \mathrm{~h}$ of darkness. Ten-day-old plants were inoculated with approximately $250 \mathrm{~J} 2 \mathrm{H}$. schachtii nematodes per root system. Inoculated plants were kept under the same conditions for an additional 3 weeks, and then, the numbers of female nematodes per plant were scored, using a dissecting microscope. The numbers of female nematodes developed on each transgenic line were used to calculate nematode susceptibility levels relative to wild-type control plants, using unadjusted paired $t$ tests on SAS with $P$ value $<0.05$ for significance.

\section{2×GFP movement assay, callose detection, and confocal microscopy.}

Upper leaves displaying the silencing phenotype or similar leaves in nonsilenced (control) or OE plants were infiltrated with agrobacterium-containing constructs encoding $2 \times \mathrm{GFP}$ at $\mathrm{OD}_{600}=0.0001,2$ weeks after VIGS induction. GFP fluorescence in plant tissues was viewed at approximately $43 \mathrm{hpi}$. Confocal analysis was performed on a Leica SP8 confocal microscope, using a 488-nm excitation laser for GFP with emission maximum at $509 \mathrm{~nm}$. At least $102 \times$ GFP foci in each of three independent experiments were imaged for each plant line. Whole leaves from control, TRV-ISE2, OE1, or OE3 plants were cut at the petiole, were placed immediately in a $0.1-\mathrm{mg} / \mathrm{ml}$ solution of aniline blue in $67 \mathrm{mM} \mathrm{K}_{3} \mathrm{PO}_{4}, \mathrm{pH} 9.5$. Tissues were stained in the dark for $10 \mathrm{~min}$ and were then observed under a confocal microscope. Aniline blue fluorescence was detected using a $\times 25$ objective and 405-nm laser excitation with a 420- to 480-nm band-pass emission filter.

\section{Syncytium measurements and callose detection.}

The sizes of single-female, fully-developed syncytia were determined as previously described (Hewezi et al. 2008). Briefly, 3 weeks postinfection with $H$. schachtii, 10 syncytia were randomly selected from ISE2 overexpression plants and wild-type Col-0 plants and were imaged using differential interference contrast (DIC) microscopy. For DIC microscopy, infected Arabidopsis roots were fixed overnight in ethanol/acetic acid (9:1) and were cleared in a chloral hydrate solution (chloral hydrate/water/glycerol, 8:1:1) for approximately $24 \mathrm{~h}$. Structure of syncytia was observed using a Nikon Eclipse 80i microscope with DIC optics, and pictures were obtained with a 12-megapixel cooled color DXM-1200c (Nikon) camera. The size of syncytia was measured using NSI-Elements BR 2.30. Callose deposition at the cell wall of the syncytia was visualized in chloral hydrate-cleared tissues neutralized in $1 \mathrm{M}$ Tris$\mathrm{HCl}$ buffer ( $\mathrm{pH} 7.5)$ and was stained with aniline blue as described above.

\section{ACKNOWLEDGMENTS}

We thank J. Dangl and S. Leibis for providing P. syringae DC3000, and J. Carrington for providing the TuMV-GFP plasmid. The authors thank the Donald Danforth Plant Science Center, St. Louis, MO, U.S.A. for plant hormone analysis. This material is based upon work supported by the National Science Foundation under grant number DBI- 427621 for acquisition of the QTRAP liquid chromatography-tandem mass spectrometry. A National Science Foundation award 1456761 to T. Burch-Smith supported this research.

\section{LITERATURE CITED}

Aguilar, E., Almendral, D., Allende, L., Pacheco, R., Chung, B. N., Canto, T., and Tenllado, F. 2015. The P25 protein of Potato virus X (PVX) is the main pathogenicity determinant responsible for systemic necrosis in PVX-associated synergisms. J. Virol. 89:2090-2103.

Alazem, M., and Lin, N. S. 2015. Roles of plant hormones in the regulation of host-virus interactions. Mol. Plant Pathol. 16:529-540.

Ali, M. A., Abbas, A., Kreil, D. P., and Bohlmann, H. 2013. Overexpression of the transcription factor RAP2.6 leads to enhanced callose deposition 
in syncytia and enhanced resistance against the beet cyst nematode Heterodera schachtii in Arabidopsis roots. BMC Plant Biol. 13:47.

Bayer, E. M., Bottrill, A. R., Walshaw, J., Vigouroux, M., Naldrett, M. J., Thomas, C. L., and Maule, A. J. 2006. Arabidopsis cell wall proteome defined using multidimensional protein identification technology. Proteomics 6:301-311.

Benitez-Alfonso, Y., Cilia, M., San Roman, A., Thomas, C., Maule, A., Hearn, S., and Jackson, D. 2009. Control of Arabidopsis meristem development by thioredoxin-dependent regulation of intercellular transport. Proc. Natl. Acad. Sci. U.S.A. 106:3615-3620.

Bhat, S., Folimonova, S. Y., Cole, A. B., Ballard, K. D., Lei, Z., Watson, B. S., Sumner, L. W., and Nelson, R. S. 2013. Influence of host chloroplast proteins on Tobacco mosaic virus accumulation and intercellular movement. Plant Physiol. 161:134-147.

Bishopp, A., Lehesranta, S., Vatén, A., Help, H., El-Showk, S., Scheres, B., Helariutta, K., Mähönen, A. P., Sakakibara, H., and Helariutta, Y. 2011. Phloem-transported cytokinin regulates polar auxin transport and maintains vascular pattern in the root meristem. Curr. Biol. 21:927-932.

Bobik, K., and Burch-Smith, T. M. 2015. Chloroplast signaling within, between and beyond cells. Front. Plant Sci. 6:781.

Brunkard, J. O., Runkel, A. M., and Zambryski, P. C. 2015. The cytosol must flow: Intercellular transport through plasmodesmata. Curr. Opin. Cell Biol. 35:13-20.

Burch-Smith, T. M., Brunkard, J. O., Choi, Y. G., and Zambryski, P. C. 2011. Organelle-nucleus cross-talk regulates plant intercellular communication via plasmodesmata. Proc. Natl. Acad. Sci. U.S.A. 108:E1451E1460.

Burch-Smith, T. M., Cui, Y., and Zambryski, P. C. 2012. Reduced levels of class 1 reversibly glycosylated polypeptide increase intercellular transport via plasmodesmata. Plant Signal. Behav. 7:62-67.

Burch-Smith, T. M., and Zambryski, P. C. 2010. Loss of INCREASED SIZE EXCLUSION LIMIT (ISE)1 or ISE2 increases the formation of secondary plasmodesmata. Curr. Biol. 20:989-993.

Caplan, J. L., Kumar, A. S., Park, E., Padmanabhan, M. S., Hoban, K. Modla, S., Czymmek, K., and Dinesh-Kumar, S. P. 2015. Chloroplast stromules function during innate immunity. Dev. Cell 34:45-57.

Caplan, J. L., Mamillapalli, P., Burch-Smith, T. M., Czymmek, K., and Dinesh-Kumar, S. P. 2008. Chloroplastic protein NRIP1 mediates innate immune receptor recognition of a viral effector. Cell 132:449-462.

Carella, P., Wilson, D. C., and Cameron, R. K. 2015. Mind the gap: Signal movement through plasmodesmata is critical for the manifestation of SAR. Plant Signal. Behav. 10:e1075683.

Carlotto, N., Wirth, S., Furman, N., Ferreyra Solari, N., Ariel, F., Crespi, M., and Kobayashi, K. 2016. The chloroplastic DEVH-box RNA helicase INCREASED SIZE EXCLUSION LIMIT 2 involved in plasmodesmata regulation is required for group II intron splicing. Plant Cell Environ. 39:165-173.

Chan, K. X., Phua, S. Y., Crisp, P., McQuinn, R., and Pogson, B. J. 2016. Learning the languages of the chloroplast: Retrograde signaling and beyond. Annu. Rev. Plant Biol. 67:25-53.

Coudert, Y., Palubicki, W., Ljung, K., Novak, O., Leyser, O., and Harrison, C. J. 2015. Three ancient hormonal cues co-ordinate shoot branching in a moss. eLife 4:e06808.

Dinesh-Kumar, S. P., Tham, W. H., and Baker, B. J. 2000. Structurefunction analysis of the tobacco mosaic virus resistance gene $N$. Proc. Natl. Acad. Sci. U.S.A. 97:14789-14794.

Ellinger, D., Naumann, M., Falter, C., Zwikowics, C., Jamrow, T., Manisseri, C., Somerville, S. C., and Voigt, C. A. 2013. Elevated early callose deposition results in complete penetration resistance to powdery mildew in Arabidopsis. Plant Physiol. 161:1433-1444.

Faulkner, C. 2013. Receptor-mediated signaling at plasmodesmata. Front. Plant Sci. 4:521.

Han, X., Hyun, T. K., Zhang, M., Kumar, R., Koh, E. J., Kang, B. H., Lucas, W. J., and Kim, J. Y. 2014. Auxin-callose-mediated plasmodesmal gating is essential for tropic auxin gradient formation and signaling. Dev. Cell 28:132-146.

Heinlein, M. 2015. Plant virus replication and movement. Virology 479480:657-671.

Heinlein, M., Padgett, H. S., Gens, J. S., Pickard, B. G., Casper, S. J., Epel, B. L., and Beachy, R. N. 1998. Changing patterns of localization of the tobacco mosaic virus movement protein and replicase to the endoplasmic reticulum and microtubules during infection. Plant Cell 10:1107-1120.

Hewezi, T. 2015. Cellular signaling pathways and posttranslational modifications mediated by nematode effector proteins. Plant Physiol. 169:1018-1026.

Hewezi, T., Howe, P., Maier, T. R., Hussey, R. S., Mitchum, M. G., Davis, E. L., and Baum, T. J. 2008. Cellulose binding protein from the parasitic nematode Heterodera schachtii interacts with Arabidopsis pectin methylesterase: Cooperative cell wall modification during parasitism. Plant Cell 20:3080-3093.

Hewezi, T., Piya, S., Richard, G., and Rice, J. H. 2014. Spatial and temporal expression patterns of auxin response transcription factors in the syncytium induced by the beet cyst nematode Heterodera schachtii in Arabidopsis. Mol. Plant Pathol. 15:730-736.

Hipper, C., Brault, V., Ziegler-Graff, V., and Revers, F. 2013. Viral and cellular factors involved in phloem transport of plant viruses. Front. Plant Sci. 4:154

Hofmann, J., and Grundler, F. M. 2006. Females and males of root-parasitic cyst nematodes induce different symplasmic connections between their syncytial feeding cells and the phloem in Arabidopsis thaliana. Plant Physiol. Biochem. 44:430-433.

Hofmann, J., Youssef-Banora, M., de Almeida-Engler, J., and Grundler, F. M. 2010. The role of callose deposition along plasmodesmata in nematode feeding sites. Mol. Plant-Microbe Interact. 23:549-557.

Hoth, S., Schneidereit, A., Lauterbach, C., Scholz-Starke, J., and Sauer, N. 2005. Nematode infection triggers the de novo formation of unloading phloem that allows macromolecular trafficking of green fluorescent protein into syncytia. Plant Physiol. 138:383-392.

Hoth, S., Stadler, R., Sauer, N., and Hammes, U. Z. 2008. Differential vascularization of nematode-induced feeding sites. Proc. Natl. Acad. Sci. U.S.A. 105:12617-12622.

Kehr, J., and Buhtz, A. 2008. Long distance transport and movement of RNA through the phloem. J. Exp. Bot. 59:85-92.

Kim, I., Hempel, F. D., Sha, K., Pfluger, J., and Zambryski, P. C. 2002 Identification of a developmental transition in plasmodesmatal function during embryogenesis in Arabidopsis thaliana. Development 129:12611272

Kobayashi, K., Otegui, M. S., Krishnakumar, S., Mindrinos, M., and Zambryski, P. 2007. INCREASED SIZE EXCLUSION LIMIT 2 encodes a putative DEVH box RNA helicase involved in plasmodesmata function during Arabidopsis embryogenesis. Plant Cell 19:1885-1897.

Komatsu, K., Hashimoto, M., Ozeki, J., Yamaji, Y., Maejima, K., Senshu, H., Himeno, M., Okano, Y., Kagiwada, S., and Namba, S. 2010. Viralinduced systemic necrosis in plants involves both programmed cell death and the inhibition of viral multiplication, which are regulated by independent pathways. Mol. Plant-Microbe Interact. 23:283-293.

Krenz, B., Jeske, H., and Kleinow, T. 2012. The induction of stromule formation by a plant DNA-virus in epidermal leaf tissues suggests a novel intra- and intercellular macromolecular trafficking route. Front Plant Sci. 3:291.

Lee, J. Y. 2015. Plasmodesmata: A signaling hub at the cellular boundary. Curr. Opin. Plant Biol. 27:133-140.

Lee, J. Y., and Lu, H. 2011. Plasmodesmata: The battleground against intruders. Trends Plant Sci. 16:201-210.

Lee, J. Y., Wang, X., Cui, W., Sager, R., Modla, S., Czymmek, K., Zybaliov, B., van Wijk, K., Zhang, C., Lu, H., and Lakshmanan, V. 2011. A plasmodesmata-localized protein mediates crosstalk between cell-to-cell communication and innate immunity in Arabidopsis. Plant Cell 23: 3353-3373

Lellis, A. D., Kasschau, K. D., Whitham, S. A., and Carrington, J. C. 2002. Loss-of-susceptibility mutants of Arabidopsis thaliana reveal an essential role for eIF(iso)4E during potyvirus infection. Curr. Biol. 12: 1046-1051.

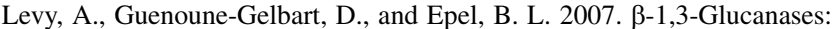
Plasmodesmal gate keepers for intercellular communication. Plant Signal. Behav. 2:404-407.

Lim, G. H., Shine, M. B., de Lorenzo, L., Yu, K., Cui, W., Navarre, D., Hunt, A. G., Lee, J. Y., Kachroo, A., and Kachroo, P. 2016 Plasmodesmata localizing proteins regulate transport and signaling during systemic acquired immunity in plants. Cell Host Microbe 19: 541-549.

Liu, Y., Burch-Smith, T., Schiff, M., Feng, S., and Dinesh-Kumar, S. P. 2004. Molecular chaperone Hsp90 associates with resistance protein N and its signaling proteins SGT1 and Rar1 to modulate an innate immune response in plants. J. Biol. Chem. 279:2101-2108

Lucas, W. J., and Lee, J. Y. 2004. Plasmodesmata as a supracellular control network in plants. Nat. Rev. Mol. Cell Biol. 5:712-726.

Manfre, A., Glenn, M., Nuñez, A., Moreau, R. A., and Dardick, C. 2011. Light quantity and photosystem function mediate host susceptibility to Turnip mosaic virus via a salicylic acid-independent mechanism. Mol. Plant-Microbe Interact. 24:315-327.

Murphy, A. M., and Carr, J. P. 2002. Salicylic acid has cell-specific effects on Tobacco mosaic virus replication and cell-to-cell movement. Plant Physiol. 128:552-563.

Nomura, H., Komori, T., Uemura, S., Kanda, Y., Shimotani, K., Nakai, K., Furuichi, T., Takebayashi, K., Sugimoto, T., Sano, S., Suwastika, I. N., 
Fukusaki, E., Yoshioka, H., Nakahira, Y., and Shiina, T. 2012. Chloroplast-mediated activation of plant immune signalling in Arabidopsis. Nat. Commun. 3:926.

Oka, K., Kobayashi, M., Mitsuhara, I., and Seo, S. 2013. Jasmonic acid negatively regulates resistance to Tobacco mosaic virus in tobacco. Plant Cell Physiol. 54:1999-2010.

Pfaffl, M. W. 2001. A new mathematical model for relative quantification in real-time RT-PCR. Nucleic Acids Res. 29:e45.

Raffaele, S., Bayer, E., Lafarge, D., Cluzet, S., German Retana, S., Boubekeur, T., Leborgne-Castel, N., Carde, J. P., Lherminier, J., Noirot, E., Satiat-Jeunemaître, B., Laroche-Traineau, J., Moreau, P., Ott, T., Maule, A. J., Reymond, P., Simon-Plas, F., Farmer, E. E., Bessoule, J. J., and Mongrand, S. 2009. Remorin, a Solanaceae protein resident in membrane rafts and plasmodesmata, impairs Potato virus $X$ movement. Plant Cell 21:1541-1555.

Reinero, A., and Beachy, R. N. 1986. Association of TMV coat protein with chloroplast membranes in virus-infected leaves. Plant Mol. Biol. 6: 291-301.

Reinero, A., and Beachy, R. N. 1989. Reduced photosystem II activity and accumulation of viral coat protein in chloroplasts of leaves infected with tobacco mosaic virus. Plant Physiol. 89:111-116.

Rojas, C. M., Senthil-Kumar, M., Tzin, V., and Mysore, K. S. 2014. Regulation of primary plant metabolism during plant-pathogen interactions and its contribution to plant defense. Front. Plant Sci. 5:17.

Schoelz, J. E., and Zaitlin, M. 1989. Tobacco mosaic virus RNA enters chloroplasts in vivo. Proc. Natl. Acad. Sci. U.S.A. 86:4496-4500.

Sewelam, N., Jaspert, N., Van Der Kelen, K., Tognetti, V. B., Schmitz, J., Frerigmann, H., Stahl, E., Zeier, J., Van Breusegem, F., and Maurino, V. G. 2014. Spatial $\mathrm{H}_{2} \mathrm{O}_{2}$ signaling specificity: $\mathrm{H}_{2} \mathrm{O}_{2}$ from chloroplasts and peroxisomes modulates the plant transcriptome differentially. Mol. Plant 7:1191-1210.

Shanks, C. M., Rice, J. H., Zubo, Y., Schaller, G. E., Hewezi, T., and Kieber, J. J. 2016. The role of cytokinin during infection of Arabidopsis thaliana by the cyst nematode Heterodera schachtii. Mol. Plant-Microbe Interact. 29:57-68.

Siddique, S., Radakovic, Z. S., De La Torre, C. M., Chronis, D., Novák, O., Ramireddy, E., Holbein, J., Matera, C., Hütten, M., Gutbrod, P., Anjam, M. S., Rozanska, E., Habash, S., Elashry, A., Sobczak, M., Kakimoto, T., Strnad, M., Schmülling, T., Mitchum, M. G., and Grundler, F. M. 2015. A parasitic nematode releases cytokinin that controls cell division and orchestrates feeding site formation in host plants. Proc. Natl. Acad. Sci. U.S.A. 112:12669-12674.
Sijmons, P., Grundler, F. M. W., von Mende, N., Burrows, P., and Wyss, U. 1991. Arabidopsis thaliana as a new model host for plant-parasitic nematodes. Plant J. 1:245-254.

Stonebloom, S., Brunkard, J. O., Cheung, A. C., Jiang, K., Feldman, L., and Zambryski, P. 2012. Redox states of plastids and mitochondria differentially regulate intercellular transport via plasmodesmata. Plant Physiol. 158:190-199.

Szakasits, D., Heinen, P., Wieczorek, K., Hofmann, J., Wagner, F., Kreil, D. P., Sykacek, P., Grundler, F. M., and Bohlmann, H. 2009. The transcriptome of syncytia induced by the cyst nematode Heterodera schachtii in Arabidopsis roots. Plant J. 57:771-784.

Thomas, C. L., Bayer, E. M., Ritzenthaler, C., Fernandez-Calvino, L., and Maule, A. J. 2008. Specific targeting of a plasmodesmal protein affecting cell-to-cell communication. PLoS Biol. 6:e7.

Torres, M. A., Jones, J. D., and Dangl, J. L. 2006. Reactive oxygen species signaling in response to pathogens. Plant Physiol. 141:373-378.

Wan, J., Cabanillas, D. G., Zheng, H., and Laliberté, J. F. 2015. Turnip mosaic virus moves systemically through both phloem and xylem as membrane-associated complexes. Plant Physiol. 167:1374-1388.

Wang, X., Sager, R., Cui, W., Zhang, C., Lu, H., and Lee, J. Y. 2013. Salicylic acid regulates plasmodesmata closure during innate immune responses in Arabidopsis. Plant Cell 25:2315-2329.

Wubben, M. J., 2nd, Rodermel, S. R., and Baum, T. J. 2004. Mutation of a UDP-glucose-4-epimerase alters nematode susceptibility and ethylene responses in Arabidopsis roots. Plant J. 40:712-724.

Wubben, M. J., 2nd, Su, H., Rodermel, S. R., and Baum, T. J. 2001 Susceptibility to the sugar beet cyst nematode is modulated by ethylene signal transduction in Arabidopsis thaliana. Mol. Plant-Microbe Interact. 14:1206-1212.

Yadav, S. R., Yan, D., Sevilem, I., and Helariutta, Y. 2014. Plasmodesmatamediated intercellular signaling during plant growth and development. Front. Plant Sci. 5:44.

Zavaliev, R., Sagi, G., Gera, A., and Epel, B. L. 2010. The constitutive expression of Arabidopsis plasmodesmal-associated class 1 reversibly glycosylated polypeptide impairs plant development and virus spread. J. Exp. Bot. 61:131-142.

Zhao, J., Liu, Q., Zhang, H., Jia, Q., Hong, Y., and Liu, Y. 2013. The Rubisco small subunit is involved in tobamovirus movement and $T m-2^{2}$ mediated extreme resistance. Plant Physiol. 161:374-383.

Zhao, J., Zhang, X., Hong, Y., and Liu, Y. 2016. Chloroplast in plant-virus interaction. Front. Microbiol. 7:1565. 